\title{
Analyses and research of the library information security system under the network environment
}

\author{
Chunmei Wang ${ }^{1}$ \\ ${ }^{1}$ Jilin Agricultural University, Changchun, Jilin Province, China
}

Keywords: The network environment, library, information system, information security.

\begin{abstract}
In the modern network environment, library management information system needs to be turned its focus to the development and utilization of information resources. The Internet can help readers' online library and the demand of the subscription, but function to meet these requirements at the same time, also must have a can provide security for user security, privacy and confidentiality of network library user's information management system. How to build and perfect the information resources, how to make the teachers and students in colleges and universities and reasonable utilization of electronic resources, improve the use and effectiveness of electronic resources is the main content of this paper to discuss.
\end{abstract}

\section{Introduction}

Manager is known both management in 21 century, and multiple applications of information technology talents, the management information system is the important tool of management personnel at all levels of management. Management information system is a composed of people and computer, able to information collection, transmission, storage, processing, maintenance and use of information systems. It can be measured enterprise's operation, the use of the past data to predict the future, starting from the global aid decision making; the use of information control the behavior of the enterprise, help enterprise to achieve the goal of long-term planning [1]. Management work of the success or failure depends on can make effective decisions, decisions correctly or not depends largely on the quality of information, management information system will formally information resources for effective management and organization of the computer system.

Management information system is becoming more and more used in many fields. Life in the colleges and universities in the process of learning, the library is an essential place, is also the biggest place to people to help. Library records the human history of civilization, in the process of thought and knowledge, the main face of objects is students, the teacher [1]. School library information management systems are one of the information management systems, and also include the establishment and maintenance of database and front-end application development. The establishment of the backstage database to have strong data consistency and integrity, data security good database, and front-end application development requires the application fully functional, simple operation, have the function that is convenient to use. Have to develop this system can help users reasonable utilization of electronic resources; improve the use and effectiveness of the electronic resources.

\section{The present situation of the library information management system}

In terms of current existing library information management system, is mainly run in DOS environment of software and software running under the Windows interface. Of our country are mainly used in the school library under the environment of DOS system, such as Tsinghua university, east China normal university, the introduction of Japan's Fujitsu used in small machines ILIS library computer management system, document information center, Chinese academy of sciences, the introduction of Taiwan's technology transfer company of the TOTALS integrated library automation 
system or a SULCMIS microcomputer network system of library development of Shenzhen university, Beijing institute of interest in the electronic information development of GLIS [1].

Automation of library information management system is the inevitable trend of the now, many colleges and universities have introduced the management mode. And the use of the various kinds of electronic resources is one of the key aspects of our library information management system will increase a lot of the introduction of electronic resources, also opened China journal net full-text database, at the same time trial with ten thousand square data knowledge service platform, leather book database, the international digital video library and search the super resources such as virtual electronic library, for the convenience of the students [2]. To meet the needs of windowed, network, now the trial information management system function is also increasing. Variety of information resources of information search, capture, has greatly increased, the content of all kinds of information management system, performance, price, operating environment has changed a lot, from the aspects such as reflected in different degrees the use of the latest technology in the world.

With the rapid development of network technology, library work also there has been a fundamental change, the original integrated system already cannot adapt to the situation of library's new changes increasingly exposed, the domestic and foreign some developer started a new generation of network update, upgrade and development of library information management system, and gradually started to launch more mature client and server mode of library information management system [2]. System upgrade is not represents the progress of the trial, because of man-made or objective reason, the library information management system in use process still exist many problems, these problems may lead to low use of electronic resources or lack of effectiveness, through summarizing, found the following problem.

Information system security is not high. Information system security problems are widespread in the hardware environment, the operating system and application software, data processing, system configuration, the user management and so on multiple levels, generally there is some features [3]:

1) Dynamic. Information system will be as the change of configuration and operation as well as the hardware and software update and brings new security issues, and will transfer between at all levels in the system, make security and prevent problems always in a dynamic development. Due to the development of network technology make people's activity is no longer subject to geographical restrictions of time and space, attacks on information systems often happens anytime and anywhere.

2) Timeliness. Information systems security concerns with the use of the user and the passage of time, in the original problem is resolved at the same time, the new hidden dangers are found, and the information system of safety problems with timeliness and exist for a long time.

3) Complexity. Due to the complex information system structure, presents the security problem also is complex, so safety is complicated system engineering.

4) Concealment. Foreign aggression are often mixed in a large number of normal network traffic and data access, make the wrongdoing and difficult to be found, thus has strong cover and concealment.

5) Diversity. Information system security problem in the hardware environment, software applications, data management and so on various aspects have different reflected, and online attacks, the spread of the virus, illegal invasion of security problems, such as growth, with the increasingly diversified trend.

6) Relativity. Safety is relative, risk is absolute, and there is no absolute safety, only the relative safety.

Lack of awareness of staff. For the network technology, the school library or used to the traditional idea of that kind of thinking mode, although has the library information management system, but not many people use, more not take knowledge as information and then divided into public information, each system hinders the school library resources sharing, or Shared is not enough, lead to waste of resources [3]. Actually a lot of foreign teachers' resources cannot very good sharing, on the one hand, because we will finally reference books resources will need a lot of financial support. On the other hand, the tide of information, and advances in technology and let's not good to accept 
changing information environment, so a lot of the library staff also like the status quo, unwilling to change their working methods, to some extent this also prevents the application and development of the information management system in the library.

Communication is not strong enough. The spread of type for public information without professional and specialization, network brings us is the sharing of resources, and due to the lack of communication, cause is the electronic reading room and other system, but with less, or the use of inadequate. Management information system, after all, is a closely related and computer technology, to master this door technology is relatively difficult [4]. Even if one command of the advanced modern technology, perhaps because of the management information system in the field of many enterprises cannot very good application, so, these have mastered advanced technology talents had nowhere to go. Don't have a lot of people to master this door technology, nor have good spread this two reasons make management information system is not widely spread in many areas, including its library.

Imperfect information service mode. Library information management system requirements for each user to targeted services, such as user what major or often see what type of book, after the statistical records, can be collected in the library after the content to remind users, achieve "information for someone to", the purpose of convenience of customers. Now, however, information system cannot do good "convenient" instead [4].

The quality of information consultants. Library information consultant is facing users the most staff, under the information society, the existing consultant quality is not enough, cannot be efficient, fast and the management of information [3]. Because many of them are new to this new technology, imagine if the information consultants cannot be good for those who are in the library staff to provide good service, so students are not very good application in the library information management system function, so it is very convenient information systems do not work well. So, it is important to the quality of information consultants.

\section{Information system security solutions}

In the school library information management system in use, to constantly improve and enhance the absorption, make the information management system can better service to the users, sums up the following countermeasures.

Safety awareness. The school library staff in the information system to improve at the same time, strengthen the awareness of this profession. In collection and transfer information science, provides the cultural entertainment, to adapt to the knowledge society and knowledge economy era, by spreading information to promote more users, increased information and so on various aspects of the user's knowledge [5].

To strengthen information communication. The transmission of information is a variety of ways, in the existing information management system, can increase the service project, such as increased information push service, vertical information service, and network intelligent knowledge service, etc. Use the network information technology, according to the user's information needs and information of interest, by the system or artificial targeted search on the net, and through the network, to provide customers with the latest information service [5].

To strengthen information sharing. Now although increased knowledge of library information service network links such as database, but not enough, you can through the union, exchange of information resources, increase share, convenient to more users, making service and resource utilization is truly full [4].

Training consulting talents. The information management of university library in continuously toward virtualization, consulting of various network approach consultant to can adapt and understand, and reference services, such as such as BBS, OICQ, strengthen personal qualities consultant, to improve the construction of online reference service, improve the quality of network applications, better service for the user [2].

Strengthen the library network security technology. Due to the network many unsafe factors, makes the network users must take corresponding network security technology to plug up loopholes 
in security and provide secure communication services [1]. Today, rapid development of network security technology can from different angles to ensure the library network information shall not be infringed upon, the basic technology of network security mainly include network encryption technology, firewall technology, operating system security kernel technology, authentication technology, network anti-virus technology.

\section{The library network information security overall design}

Network encryption technology is one of the most effective technologies in network security. An encrypted network, not only can prevent unauthorized users wiretapping and into the net, but also deal with one of the effective methods of malicious software. Is the purpose of the network information encryption protection network data, files, password, and control information, and protect the online transmission of data. Information encryption process is a concrete implementation by all kinds of encryption algorithms, it provides very strong with a small price protection. In most cases, information encryption is the only way to ensure the confidentiality of information.

Overall design is the overall idea of the construction of university library computer network and engineering blueprint, is the central task of the construction of the university library computer network [6]. For overall design of university library computer network, first of all, research object and demand investigation, find out the nature of the library, tasks and characteristics of the reform and development, to accurate description of library informationization environment, clear requirements and conditions of the system construction; Secondly, based on the analysis of application requirements, determine the Intranet service type, and determine the system of the construction of the concrete goal, including the network facilities, site setting, application development and management of target; Third, network topology structure and function is determined, according to application requirements, the construction goal and the main library building distribution characteristic, carries on the system analysis and design; Fourth, determine the technical design principle of requirements, such as in the technology selection, layout design, equipment selection, software configuration and other aspects of the standards and requirements; Fifth, planning arrangements for the construction of university library computer network implementation steps.

Firewall technology. Firewall technology is to set up a barrier between the protected network and the outside world, through the combination of computer hardware and software to set up a security gateway, which protect the internal network from the invasion of illegal users, it can identify, limit, change of data flow across the firewall, real how secure communications network to the development of computer communication network is especially important for the future. The composition of the firewall can be expressed as: filter firewall + gateway security strategy, it is a kind of very effective network security technology [6]. On the Internet, through which to isolate risk area and safety area connection, but don't hamper people access to risk area. Firewall can control access to network communication data, thus completed only allow safe and approved information into, at the same time resist pose a threat to the enterprise data into the task.

Operating system security kernel technology. Operating system security kernel technology in addition to the traditional network security technology, people began to consider network security at the operating system level, try to put the system may cause safety issues in the kernel part is removed from the kernel, which make the system safer [6]. Operating system platform security measures include: the high security of the operating system; the safety of the operating system configuration; using the security check operating system vulnerability scanning system, etc.

Authentication technology. Authentication technology is the processes of the user to the system produce their identity. Identity authentication is the process of system audit user identification [5]. The two processes are ascertained and confirm the identity of the two communicating parties' important link; people often see these two works collectively referred to as authentication. Its security mechanism is the first to authenticate a user request, to confirm whether it for legitimate users, so legitimate users, to review whether the user has the right to the requested service or host a visit to him, in order to prevent some illegal invasion of intrusion. 
Network anti-virus technology. Under the network environment, the computer virus has immeasurable threatening and destructive power. $\mathrm{CIH}$ virus is enough to prove that if do not take the computer network anti-virus, that may cause disastrous consequences to the society, so the computer virus prevention is also a important part of the network security technology. Concrete implementation method of network anti-virus technology including the network server files are frequently in a scanning and monitoring workstation adopts anti-virus chip and Settings for web directory and file access, etc [6]. Anti-virus must consider, from the network as a whole can for the convenience of management personnel, in the night of entire network client to scan, check virus; Use online alarm function, every machine on the network failure, viruses, network managers can know in time, to be resolved from the management center.

\section{Summary}

Library information management system is a better service for the user, convenient for users, make full use of resources is the most fundamental purpose. To improve the effectiveness of the electronic resources and exploitation degree is the goal we have been, in the development of the information management system, to constantly improve, advancing with The Times, the library information management and the world, improve the staff's personal quality, in this era of knowledge economy can better service for the user.

\section{References}

[1] T. T. Yang, Computer and network security, Chongqing: Chongqing university press, 2010, vol. 4, pp. 12-16.

[2] X. F. Chen, The design of the electronic reading room and the service in the information age, medical equipment information, 2012, vol. 4, pp.24-27.

[3] H. X. Ding, The university library under the network technology and information management, Journal of library of China, 2012, vol. 2, pp. 32-35.

[4] F. F. Wang, Try to talk about the current situation of university library computer information management team and construction, Henan books' publication, 2013, vol. 3, pp. 23-26.

[5] W. J. Wang, The university library information management system based on network technology, Modern information, 2006, vol. 4, pp. 15-19.

[6] X. X. Qin, University library information management system and design method of research, Intelligence development of science and technology and economy, 2007, vol. 11, pp. 67-71. 